\title{
Comparative Study of Different Hormone Protocols in Anestrus Cattle (Bos indicus)
}

\section{Ashish Tanwer ${ }^{1 *}$, Mitesh Gaur ${ }^{2}$, Dinesh Kumar Jhamb², Bhupendra Bhardwaj ${ }^{4}$, Shantanu Kumar Kuldeep ${ }^{2}$ and Khushboo Panwar ${ }^{4}$}

${ }^{1}$ CVAS, Bikaner, Rajasthan Veterinary and Animal Sciences, Bikaner, Rajasthan, India

${ }^{2}$ Departments of Veterinary Gynaecology and Obstetrics, CVAS, Navania, Vallabhnagar, Udaipur, India

${ }^{3}$ Department of Animal Husbandry, Government of Rajasthan, Udaipur, India 4ANH, DSM

Nutritional Products India Private Limited, India

${ }^{4}$ Departments of Veterinary Microbiology and Biotechnology, CVAS, Bikaner, Rajasthan, India

*Corresponding author

\section{A B S T R A C T}

\section{Keywords}

Anestrus cattle,

Hormonal

protocols,

Conception rate,

Synchronization,

Fertility and

Cyclicity

\section{Article Info}

Accepted:

17 June 2020

Available Online:

10 July 2020
The present study was undertaken to study the effect of three estrus synchronization hormone protocols (GPG-48, GPG-56 and GPG-CIDR) and subsequently fertility in anestrus cattle. They were divided into three groups (16 each) which were subjected to three different estrus synchronization protocols i.e. GPG-48, GPG-56 and GPG-CIDR. Fixed time Artificial Insemination was performed as per the protocols. Experimental cows exhibiting estrus were inseminated. The conception rates were $56.25 \%, 68.75 \%$ and $37.50 \%$ in GPG-48, GPG-56 and GPGCIDR groups respectively. It is concluded that GPG-56 protocol with $68.75 \%$ conception rate was more effective than GPG-48 $(56.25 \%)$ and GPG-CIDR (37.50\%) in anestrous cattle.

\section{Introduction}

The profitable dairy farming is predominantly based on two major inter-related factors, viz., nutrition and reproduction. For economic dairy farming, exotic and indigenous dairy cows must calve regularly at every 12 to 13 months interval. Any deviation or prolongation in breeding rhythm results in progressive economic loss due to extension of open days, reduced calvings and lactations during the life span of animal. Fertility of the animal depends on evaluation of reproductive performance. 
Cattle suffer to a large extent from the reproductive disorder of post partum anoestrus city (about $75 \%$ ) which causes a great inflict on the economy to the dairy farmers (Kutty and Ramachandran, 2003). During the last few years, several studies have been attempted to treat the prolonged postpartum anestrus in cows by using hormonal treatments such as gonadotropin releasing hormone $(\mathrm{GnRH})$, estrogen, prostaglandin (PGF2 $\alpha$ ) and progesterone (Edwell et al., 2004).

Anestrus is the state of ovarian a cyclicity, reflected by complete sexual inactivity with manifestation of estrus with the absence of palpable follicular or luteal structures. Various research workers have obtained satisfactory results by the use of different hormonal preparations to stimulate the hypothalamic-pituitary-adrenal axis and initiate ovulation and resumption of normal cyclicity of anestrus in buffaloes (Singh and Singh, 1986; Aminudeen 1991). The hormones play an important role in fertility such as gonadotropin-releasing hormone $(\mathrm{GnRH})$ and prostaglandins were used to increase pregnancy rate by inducing ovulation and improving the sperm transport in the female reproductive tract. Studies have shown that administration of $\mathrm{GnRH}$ followed by PGF $2 \alpha$ increases the degree of synchrony and decreases the variability in the time to onset of estrus in lactating cows (Pursley et al., 1997) with the interval to estrus after PGF2 $\alpha$ injection averaging 3 days. A variety of progestational compounds have been administered (Malik, 2005) to mimic the luteal function by blocking the release of gonadotrophins from pituitary, so that subsequent withdrawal of these compounds may result in release of gonadotrophins to initiate follicular activity in ovaries with establishment of estrous cycles. Estrus synchronization has been used to manage reproduction in cattle and buffaloes for many years. These programmes involve various protocols for administration of single hormone or combination of hormones but results have varied among programmes and herds (Britt and Gaska, 1998). Therefore, the present study was planned to study comparative efficacy of various GPG protocols in cattle viz. GPG-48, GPG-56, GPG-CIDR in combination with different hormones for induction of estrus in cows under field conditions.

\section{Materials and Methods}

\section{Animals Selection}

A total Sixty four (64) anestrus animals were kept in different environmental and management condition i.e. Gaushala and different village condition. Those animals showing true anestrus were selected after per rectum examination of genitalia. The cows were not observed in estrus at least six months or more after parturition were considered as non cyclic animals. Animals affected with any kind of infectious disease or structural pathological abnormalities were excluded from the study.

The selected cattle were equally divided in four groups, T1, T2, T3 and T4 (16 cattle each). Group T2, T3 and T4 were treated with GPG-48, GPG-56 and GPG48+CIDR protocol respectively. T1 group was control. Fixed time artificial insemination was performed as per the protocols. All inseminated animals were examined rectal palpation and ultasonographically after 40 days for pregnancy diagnosis.

\section{Protocol Groups}

Different hormonal protocol was used in these anestrus animal are as under.

Control group: - In this group animals were 
provided regularly feeding without any hormones.

GPG 48 (Ovsynch protocol):- First injection on day zero, seven days after GnRH (Inj. Gynarich, Intas. Pharmaceuticals Ltd India) injection PGF2 $\alpha$ (Inj. Pregma, Intas Pharmaceuticals Ltd India) was administered, 48 hours after PGF2 $\alpha$, II injection of GnRH was repeated followed by two AI 12 hours apart.

GPG 56 (COsynch protocol):- First injection of $\mathrm{GnRH}$ on day zero, seven days after $\mathrm{GnRH}$ injection PGF2 $\alpha$ was administered, 56-60 hours after PGF2 $\alpha$, II injection of GnRH was repeated followed by two AI 12 hours apart.

GPG 56 + CIDR (COsynch + progesterone therapy):- First injection of GnRH on day zero, with CIDR (EAZI-BREED, Pfizer), (Intravaginal progesterone releasing device), seven days after GnRH injection PGF2 $\alpha$ was administered along with removal of CIDR, 48-50 hours after PGF2 $\alpha$, II injection of $\mathrm{GnRH}$ was repeated followed by Two AI at 12 hours apart.

Artificial insemination was done in all four groups morning evening using frozen semen of high quality bull.

\section{Results and Discussion}

It was observed that, GPG-56 protocol was more effective than other two protocols. In this group 11 out of 16 cattle conceived with resulting conception rate of $68.75 \%$.

T1- (n-16) Control Group

T2- (n-16) GPG-48 PROTOCOL (Ovsynch protocol)

T3- (n-16) GPG-56 PROTOCOL (COsynch protocol)

T4- (n-16) GPG56-CIDR PROTOCOL
(COsynch + Progesterone therapy)

Similarly GPG-48 was second most effective protocol in which 9 out of 16 cattle conceived with a conception rate of $56.25 \%$, whereas in GPG 56-CIDR protocol only 6 out of 16 cattle conceived with a conception rate $37.50 \%$. These observations suggest that the conception rate varies with different treatment protocols. Conception rate in GPG-56 and progesterone based Ovsynch with AI at observed estrus were superior when compared to progesterone based GPG-48 with FTAI, GPG 56-CIDR with FTAI with AI at observed estrus. Further, it should be noted that while instituting such treatments in field conditions, the cost of the synchronization protocol as well as the milk yield of the cow should also be taken into consideration before resorting to any such treatments. Irrespective of the treatment protocols in the present study, an overall conception rate of 30.55 per cent was obtained for anestrus; it appears pertinent that before resorting to hormonal treatments, multiple AI during observed estrus may be attempted in medium producing anestrus cattle under field conditions.

The effect of different hormonal protocol in different conception rate of each group highest conception rate GPG 56 (68.75\%) protocol followed by GPG $48(56.25 \%)$, and GPG56+CIDR (37.50\%) and control group $(0 \%)$ conception rate during this time of treatment.

In present study COsynch protocol the conception rate differ from Barolia et al., 2016 (66.66\%) and similarly reported Neglia et. al., 2003 and Baruselli at. al., 2008 (62.5\%), Sharma et al., 2017 (61.5\%), Bhatnagar et al., 2020 (61.9\%) was lower. Mathur and Srivastava 2010 (75\%) similarly finding are in agreement with those of Dantre, et al., 1998 and Thakur and Bhatt, 1999 were higher. 
Table.1

\begin{tabular}{|l|c|c|c|c|c|}
\hline Sr. No & Group & $\begin{array}{c}\text { Number of } \\
\text { animals }\end{array}$ & Conceived & $\begin{array}{c}\text { Non } \\
\text { conceived }\end{array}$ & Conception rate \\
\hline & GPG 48 & 16 & 9 & $7(43.75 \%)$ & $56.25 \%$ \\
\hline 2. & GPG 56 & 16 & 11 & $4(31.25 \%)$ & $68.75 \%$ \\
\hline 3. & $\begin{array}{c}\text { GPG56 } \\
\text { CIDR }\end{array}$ & 16 & 6 & $10(62.50 \%)$ & $37.50 \%$ \\
\hline
\end{tabular}

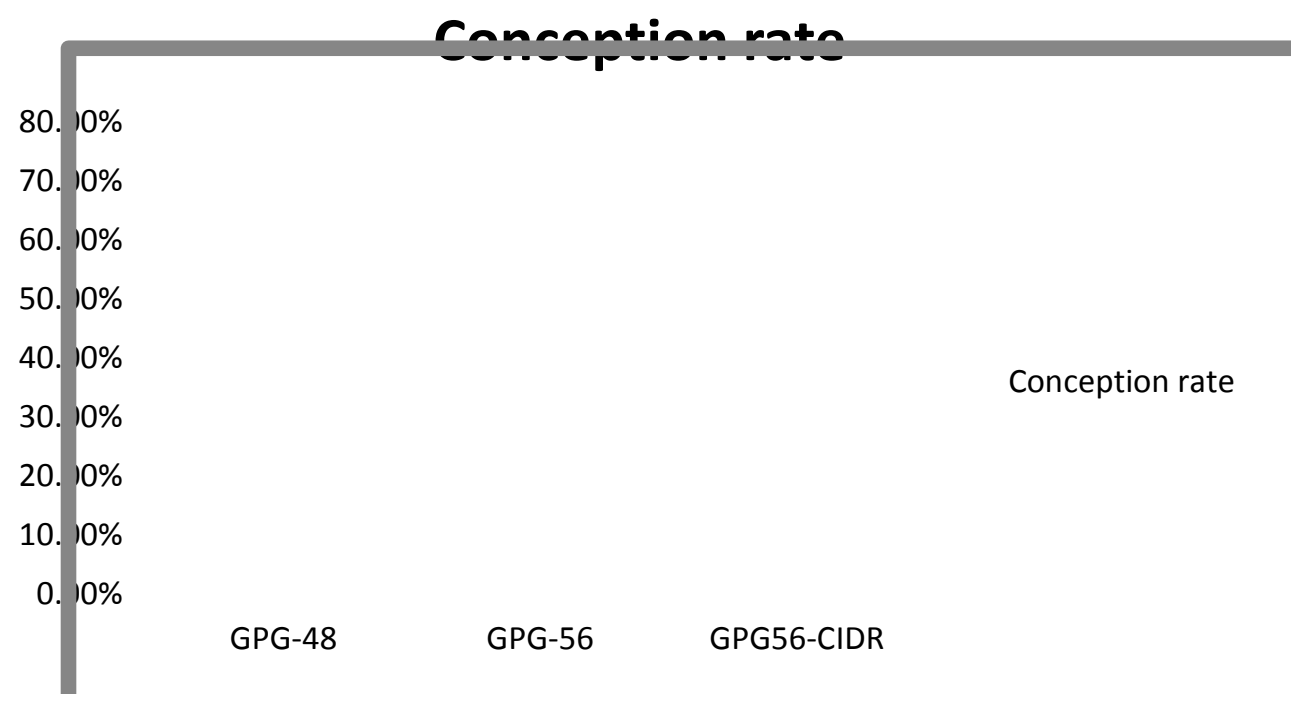

In conclusion it can be concluded that GPG56 and progesterone (EAZI-BRED) based Ovsynch with A.I at observed estrus could be implemented in dairy herds as well as in cattle of individual dairy farmers with high milk yield. Such a treatment option would definitely reduce the number of day open in anestrus cattle and enable to them to conceive at an earlier stage. This would also enhance the economy of the farmers to a greater extent. Further, multiple A.I could be implemented with appreciable conception rate in medium producing dairy cows without causing much financial constraints.

It was observed that GPG-56 protocol was more effective than other two protocols with 11 out of 16 cattle conceived $(68.75 \%)$. Similarly GPG-48 was second most effective protocol in which 9 out of $16(56.25 \%)$ cattle conceived, whereas GPG 56-CIDR was found effective in only 6 animals (37.50\%). In Control group no cow exhibited estrus during whole period of investigation.

\section{References}

20th Indian livestock census, 2019. The department of animal husbandry and dairying under ministry of fisheries.

Aminudeen (1991). Effect of gonadotrophin releasing hormone on postpartum reproductive efficiency of cross-bred cows: Clinical and endocrine aspects. Ph.D. thesis submitted to Haryana Agric. University, Hisar (India).

Barolia, Y., Shende, K., Vaishnava, C.S. and Nagda, R.K. 2016. Comparative study of Cosynch and Ovsynch Protocol on fertility in repeat breeder Gir cow. International Journal of Science, Envr. Tech. 5(4): 1874-1878.

Baruselli, P.S. (2001). Control of follicular 
development applied to reproduction biotechnologies in buffalo. Proceedings of the I congress Nazionale sull allevamento del Buffalo., Book of the congress. 128-146.

Bhatnagar, P.C., Choudhary, J. L., Bhardwaj, B., Shakhar, C., Gupta, L and Sharma , D, K (2020). Effect of different hormonal protocol and nutritional supplementation on reproduction performance of cattle under different field condition. International Journal of Current Microbiology and applied Sciences. 9(1):1511-1522

Britt, J.S. and Gaska, J. (1998). Comparison of two estrus synchronization programs in a large confinement housed dairy herd. Journal of animal veterinary Medicine Association 212:210-212

Dantre. U .K., Thakur. M. S and Pandit. R. K.(1998). Indian Journal of animal Reproduction. 19(2), 90-92.

Edwell, S.M., Slawomir, Z., and Tomasz, J., (2004). Comparative study on the efficacy of hormonal and non hormonal treatment methods in ovarian function affected dairy cows. Bulletin Veterinary Institute of Pulawy. 48, 265-267.

Kutty, C.I. and Ramachandran, K., (2003). Bovine infertility a field oriented categorization based on investigation among crossbred cattle in a district of Kerala. Indian Journal of Animal Science 73(2): 35-37.

Malik, R.K. (2005). Studies on ovarian follicular dynamics during early postpartum period, anestrus condition and hormonal therapies for induction of estrus in Murrah buffaloes (Bubalus bubalis). Ph.D. thesis submitted to CCS
Haryana Agricultural University, Hisar (India).

Mathur. A. K. and Srivastava. S. (2010). Comparative efficacy of different treatment protocols on the induction of Oestrus in anestrus Frieswal heifers. The Blue Cross Book.44-47

Neglia, G., Gasparrini, B., Di Palo, R., De, Rosa. C., Zicarelli, L. and Campanile, G. (2003). Comparison of pregnancy rates with two estrus synchronization protocols in Italian Mediterranean Buffalo and cow. Theriogenology, 60: 125-133.

Pursley, J.R., Wiltbank, M.C., Stevenson, J.S., Ottobre, J.S., Garverick, H.A. and Anderson, L.L. (1997). Pregnancy rates per artificial insemination for cows and heifers inseminated at a synchronized ovulation or synchronized estrus. Journal of Dairy Science. 80(2): 295-300.

Rathore, R., Sharma. R. K.., Phulia. S.K.., Mudgal. V., Jerome. A., Ghuman. S.P.S. and Singh. I. (2017). Comparative efficacy of oestrus synchronization protocols in buffalo (Bubalus bubalis), Tropical Animal Health and Production. 49: (7) 1377-1382.

Singh, L.P. and Singh, B.K. (1986). Studies on incidence and treatment of anestrus desi cow. Indian Veterinary of Journal 63: 961-962.

Thakur. M. S. and Bhatt. V. K. (1999). Induction of oestrus in delayed pubertal crossbred heifers treated with Receptal and long acting steroid preparation. In proceedings $\mathrm{XV}$ annual convention and national Symposium on biotechnologies in optimizing fertility in farm animals.1012.

\section{How to cite this article:}

Ashish Tanwer, Mitesh Gaur, Dinesh Kumar Jhamb, Bhupendra Bhardwaj, Shantanu Kumar Kuldeep and Khushboo Panwar. 2020. Comparative Study of Different Hormone Protocols in Anestrus Cattle (Bos indicus). Int.J.Curr.Microbiol.App.Sci. 9(07): 2122-2126. doi: https://doi.org/10.20546/ijcmas.2020.907.247 